\title{
Correction to: Performance Analysis of V2V-Based Vehicular Platoon with Modified CACC Scheme
}

Siyuan Zhou, Liangliang Xiang, and Guoping Tan

\section{Correction to: \\ Chapter "Performance Analysis of V2V-Based Vehicular Platoon with Modified CACC Scheme" in: Z. Liu et al. (Eds.): Wireless Algorithms, Systems, and Applications, LNCS 12939, https://doi.org/10.1007/978-3-030-86137-7_52}

In the originally published chapter 52 the Figure 3 did not present the information correctly. The Figure 3 has been corrected by adding a blue dotted line to the graph.

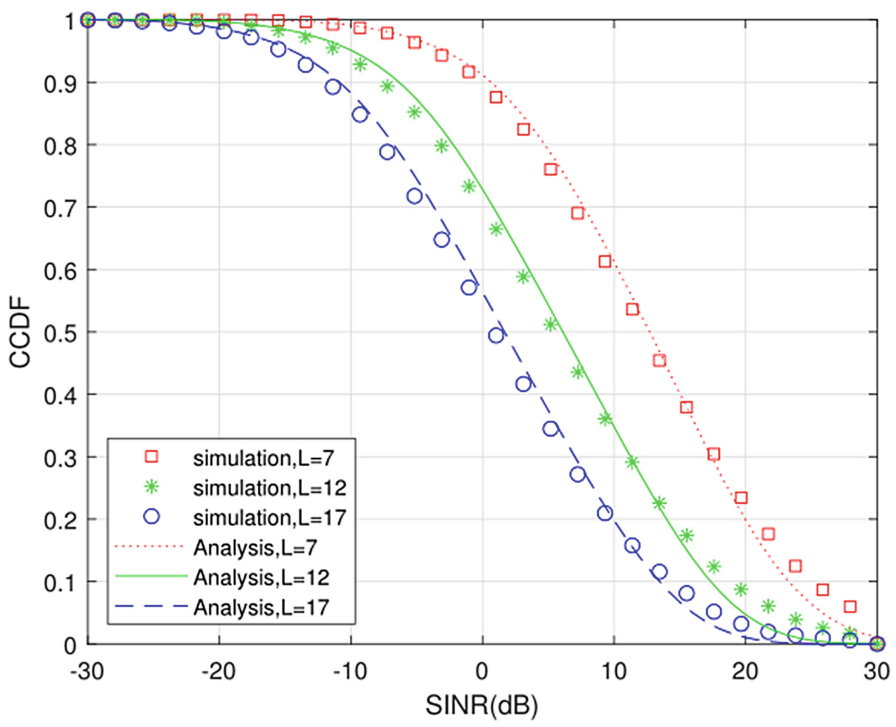

Fig. 3. The CCDF with the SINR derived in (7)

The updated version of this chapter can be found at https://doi.org/10.1007/978-3-030-86137-7_52 